\title{
Investigation of the role of nitric oxide synthase 2 in pregnancy using mutant mice
}

\author{
T. G. Burnett ${ }^{1}$, J. S. Tash ${ }^{2}$ and J. S. Hunt ${ }^{1,3^{*}}$ \\ ${ }^{1}$ Department of Anatomy and Cell Biology, ${ }^{2}$ Department of Molecular and Integrative \\ Physiology, and ${ }^{3}$ Department of Pathology and Laboratory Medicine, University of Kansas \\ Medical Center, Kansas City, KS 66160-7400, USA
}

\begin{abstract}
Nitric oxide (NO) has been implicated as a signalling molecule in many cellular processes. As nitric oxide synthase 2 (NOS-2) is the main isoform expressed in mouse decidua and metrial gland, mice with a targeted disruption of the gene encoding NOS-2 were used to determine the potential roles of this enzyme during pregnancy. Reproductive success and the morphology of implantation sites throughout pregnancy were compared in NOS-2 deficient (NOS-2-/-) and wild-type (WT) mice. Although there were no significant differences in the duration of gestation or birth weight, NOS-2/- mice had significantly fewer viable embryos at mid-gestation and delivered smaller litters than did WT mice. Histological sections of uteroplacental units from WT and NOS-2-/- mice were compared to establish the mechanisms underlying the loss of fetuses. No morphological differences were observed on day 6 or day 8 of
\end{abstract}

gestation, indicating that implantation and early development of implantation sites were unaffected by the absence of NOS-2. However, by mid-gestation, decidua of NOS-2/mice had reduced cellularity and their decidual arteries had abnormally thickened walls. These observations were quantified by morphometric measurements, which showed a significant reduction in decidual cellular area and a significant increase in the blood vessel wall : lumen ratio in NOS-2 ${ }^{-/-}$mice. The increase in the thickness of the blood vessel walls was not due to abnormal cellular infiltration or to altered expression of $\alpha$-actin in vascular smooth muscle. These results indicate that NOS-2 has a functional role in the maintenance of decidual cellular integrity and development of appropriate uterine vasculature, and may play a supportive role in promoting embryo survival.

\section{Introduction}

Nitric oxide $(\mathrm{NO})$ has been implicated in many physiological functions, including regulation of vasculature, smooth muscle quiescence, inhibition of leucocyte adhesion to endothelial cells and cellular cytotoxicity (Moncada et al., 1991; Radomski, 1995; MacMicking et al., 1997). As these processes are central to uterine changes during mammalian pregnancy, it is likely that NO has important roles during gestation. Expression of nitric oxide synthase (NOS) has been documented in placentae and pregnant uteri of many species, including humans and rodents (Hunt et al., 1997; Sladek et al., 1998; Norman et al., 1999). Furthermore, studies using NOS inhibitors have confirmed that NO synthesis is critical for normal pregnancy in rats (Yallampalli and Garfield, 1993; Molnar et al., 1994, Chwalisz et al., 1999). The precise functions of NO at the maternal-fetal interface remain obscure. However, the use of $\mathrm{NO}$ in other contexts strongly indicates that the functions of NO may facilitate the massive vascular remodelling and blood flow changes required to sustain the developing fetus.

Three NOS isoforms have been described: endothelial

${ }^{*}$ Correspondence

Email: jhunt@kumc.edu
NOS (NOS-3), inducible NOS (NOS-2) and neuronal NOS (NOS-1) (Nathan and Xie, 1994). Previous studies have shown that NOS-2 is the dominant isoform expressed in the pregnant uterus (Ali et al., 1997). In mice and rats, NOS-2 is expressed predominantly in uterine leucocytes known as uterine natural killer cells and macrophages (Hunt et al., 1997; Sladek et al., 1998). Uterine natural killer cells are found with greater frequency around uterine arterioles, and the maturation and population density of these cells reaches a peak at mid-gestation, indicating that uterine natural killer cells are spatially and temporally positioned to affect uterine vasculature (Peel, 1989). In fact, studies have shown that uterine natural killer cells and their production of interferon-gamma (IFN- $\gamma$ ) are involved in normal pregnancyinduced decidual vascularization and maintenance of decidual cellularity (Guimond et al., 1997; Ashkar et al., 2000; Greenwood et al., 2000). However, the involvement of other downstream mediators and the mechanisms involved in establishing the structural components of the decidua and its vasculature have not been elucidated.

In the present study, mice deficient in the gene encoding NOS-2 were used to evaluate the possible roles of NO during pregnancy. The possible functions of NOS-2-derived $\mathrm{NO}$ in mediating reproductive success, decidual vascular remodelling and maintenance of decidual integrity were addressed. 


\section{Materials and Methods}

\section{Animal use and tissue acquisition}

Breeding colonies of NOS-2 deficient (NOS-2--) (gift from C. Nathan, Weill Cornell Medical College, NY) and strain-matched background, C57BL/6 × 129 SvEv (The Jackson Laboratory, Bar Harbor, ME) wild-type (WT) mice were maintained following guidelines established by the Animal Use and Care Committee of the University of Kansas Medical Center. Null mice and WT mice were maintained as pure strains by homozygous matings. Virgin female mice were housed with males and pregnancy (day 1) was identified by the presence of a vaginal plug. Female mice were killed on the appropriate day of gestation. The pregnant uterus was removed and dissected manually into implantation sites containing embryo, extraembryonic membranes, placenta, decidua, metrial gland and uterine smooth muscle (uteroplacental tissue), and were then either processed for cryosectioning or were fixed in $4 \%(\mathrm{w} / \mathrm{v})$ paraformaldehyde in PBS overnight and embedded in paraffin wax on the next day. Sections of $5 \mu \mathrm{m}$ in thickness were obtained at the centre of the implantation sites. For protein isolation, mid-gestation tissues were dissected further into placenta, mesometrial decidua and metrial gland and subsequently frozen with liquid nitrogen and stored at $-80^{\circ} \mathrm{C}$ until use. The numbers of viable and resorbing embryos were determined from mice killed early in gestation, which was defined as day 6 and day 8 of gestation, or as mid-gestation, which included days 10,12 and 14 of gestation. Litter size was used to determine the number of pups carried to term. Statistical comparisons between strains with respect to the number of pups or viable embryos were determined by the $t$ test procedure and the resorption frequencies were compared by the chi-squared procedure. The birth weight of newborn pups was determined on the morning after delivery for seven litters in each strain. Birth weight data were analysed using a mixed effects ANOVA model, with strain as a fixed effect and mother as a random effect to account for clustering within litters. The model was also adjusted for the number of pups in the litter.

\section{Immunohistochemistry and histochemistry}

Unless otherwise noted, all reagents for these and all other protocols described below were obtained from Sigma Chemical Company (St Louis, MO). Paraffin wax was removed from the cross-sections of uteroplacental tissues collected from the centres of implantation sites. The tissues were then stained with periodic acid-Schiff reagent (PAS) and haematoxylin and eosin. Sections of fixed uteroplacental tissue were also stained by immunohistochemistry using antibodies specific for monocyte-macrophages (F4/80, $10 \mu \mathrm{g} \mathrm{ml}-1$ ) (Austyn and Gordon, 1981), smooth muscle $\alpha$-actin (clone 1A4, 1:500 dilution) and cytokeratin (Lu-5, $1 \mu \mathrm{g} \mathrm{ml}^{-1}$; Zymed Laboratories, San Fransisco, CA). Immunohistochemistry was performed on uteroplacental tissue from at least three WT and three NOS-2-/- mothers at day 12 of gestation. Sections to be stained with the anti-cytokeratin antibody required partial digestion with $0.25 \%(\mathrm{w} / \mathrm{v})$ trypsin at room temperature to expose the antigen. Indirect immunohistochemistry was performed by blocking with $10 \%(\mathrm{v} / \mathrm{v})$ normal serum from the species in which the secondary antibody was derived for $30 \mathrm{~min}$ at room temperature. The mouse anti-smooth muscle $\alpha$-actin and the anti-cytokeratin required the use of proprietary blocking reagents (Zymed Laboratories) to avoid secondary antibody binding to endogenous mouse IgG. The sections were then incubated with primary antibody at the concentrations indicated above or with an equal concentration of serum or matched immunoglobulin isotype (Vector Laboratories, Burlingame, CA) for $1 \mathrm{~h}$ at $37^{\circ} \mathrm{C}$. After incubation with the primary antibody or control, endogenous peroxidase activity was blocked by treating the sections with $0.5 \%(\mathrm{v} / \mathrm{v}) \mathrm{H}_{2} \mathrm{O}_{2}$ in methanol for $30 \mathrm{~min}$ at room temperature. After washing with PBS containing $0.05 \%(\mathrm{v} / \mathrm{v})$ Tween-20 (PBST), a biotinylated secondary antibody (Vector Laboratories) was applied followed by incubation with streptavidinhorseradish peroxidase conjugate (Zymed Laboratories) for $10 \mathrm{~min}$. The colour was developed by treating the sections with 3-amino-9-ethylcarbozole in N,N-dimethylformamide (AEC; Zymed Laboratories), which yields a red substrate at the site at which the antigen is present. Frozen tissue sections were tested by direct immunohistochemical analysis using a biotin-labelled anti-thrombospondin antibody (clone A6.1, $4 \mu \mathrm{g} \mathrm{ml} \mathrm{m}^{-1}$; LabVision, Fremont, CA) and biotinylated mouse IgG-I as a negative control. Sections were blocked for 30 min with $10 \%$ (v/v) normal mouse serum followed by $1 \mathrm{~h}$ incubation with primary antibody. Colour development was performed as described for indirect immunohistochemistry. Positive control slides for anti-thrombospondin staining were obtained by culturing a mouse fibroblast cell line (L929, American Type Culture Collection) on Lab-Tek chamber slides (Nunc, Rochester, NY) in Dulbecco's modified Eagle's media (DMEM) supplemented with $10 \%(\mathrm{v} / \mathrm{v})$ fetal bovine serum (FBS). After culturing for $24 \mathrm{~h}$, the cells were fixed in cold acetone and frozen until staining was performed.

\section{Image analysis}

Morphometry of decidual blood vessels and analysis of decidual cellularity was performed on digitized images of haematoxylin- and eosin-stained sections of uteroplacental tissues from NOS-2-/ and WT mice at days 8, 10, 12 and 14 of gestation using Optimus 5 image analysis software (Media Cybernetics, DelMar, CA). Separate decidual vessels were measured in two to four implantation sites from three to five mothers of each strain by an observer who was unaware of the species of origin. Decidual vessels were analysed by measuring the diameter of the lumen and the thickness of the vessel wall. Five measurements for each vessel were obtained and the data were expressed as a ratio between the average thickness of the vessel wall and the average diameter of the vessel lumen. Statistical differences 
between strains were assessed by a mixed effects repeated measures ANOVA, accounting for the random effects of the mother, implantation sites within the mother and vessels within implantation sites. Decidual cellularity was assessed by quantifying the area of decidual tissue with staining intensity above background levels. An observer unaware of the species of origin quantified the average percentage of cellular area from three areas within the decidua of each implantation site. Three implantation sites from three mothers of each strain were assessed $(n=9)$. Statistical significance of the differences observed between groups was determined by one-way ANOVA followed by Tukey's multiple comparison procedure.

\section{ELISA quantification of IFN- $\gamma$}

Metrial glands and decidua basalis were dissected carefully from implantation sites of NOS-2-/- and WT mice at day 10 and day 11 of gestation. The dissected samples were pooled by litter and placed into $1.5 \mathrm{ml}$ microcentrifuge tubes containing $10.0 \mu \mathrm{l}$ lysis buffer per implantation site (Tris-buffered saline, $\mathrm{pH} 7.4,1 \%$ (v/v) Triton-X100, 1.0 mmol ethylenediaminetetraacetic acid I-1, $1.0 \mathrm{mmol}$ ethylenebis (oxyethylenenitrilo) tetra-acetic acid $\mathrm{I}^{-1}, 0.2 \mathrm{mmol}$ phenylmethylsulphonyl fluoride $\mathrm{I}^{-1}, 0.5 \mu \mathrm{g}$ aprotonin $\mathrm{ml}^{-1}$, $0.5 \mu \mathrm{g}$ leupeptin $\mathrm{ml}^{-1}$ and $0.5 \mu \mathrm{g}$ pepstatin $\mathrm{A} \mathrm{ml}^{-1}$ ) on ice and immediately homogenized by micropestle. The resulting slurry was centrifuged at $8000 \mathrm{~g}$ for $10 \mathrm{~min}$ and the supernatant was collected for the assay. Protein concentrations were determined for each sample using the BioRad DC protein assay (BioRad Laboratories, Hercules, CA) and the samples were frozen until use. As a positive control, the supernatant was collected from a culture of mouse splenocytes cultured with $10 \mu \mathrm{g}$ concanavalin A (ConA) $\mathrm{ml}^{-1}$. The lysates were assayed for IFN- $\gamma$ by ELISA using a commercially available antibody capture and detection pair (BD Biosciences, San Diego, CA). ELISA plates were coated with $50 \mu \mathrm{l}$ per well of $2 \mu \mathrm{g}$ capture antibody (clone R4-6A4) $\mathrm{ml}^{-1}$ in $0.1 \mathrm{~mol} \mathrm{Na}{ }_{2} \mathrm{HPO}_{4} \mathrm{I}^{-1}$ overnight at $4{ }^{\circ} \mathrm{C}$. Coated plates were washed with PBST and blocked with $10 \%$ FBS for $1 \mathrm{~h}$ at room temperature. Diluted samples, recombinant mouse IFN- $\boldsymbol{\gamma}$ and ConA supernatant were added to triplicate wells (100 $\mu \mathrm{l}$ per well) and incubated overnight at room temperature. The plates were washed with PBST and incubated with $50 \mu \mathrm{l}$ per well of $0.5 \mu \mathrm{g}$ biotinylated detection antibody (clone XMG1.2) $\mathrm{ml}^{-1}$ at room temperature for $1 \mathrm{~h}$. The plates were washed thoroughly and then incubated with $100 \mu \mathrm{l}$ per well of horseradish peroxidase-avidin D (Vector Laboratories) diluted at 1:3000 for $30 \mathrm{~min}$ at room temperature. After washing eight times with PBST, $100 \mu \mathrm{l}$ 2,2'-azino (3-ethylbenzthiazoline-6-sulphonic acid) (ABTS) substrate (Sigma, ready to use formulation) was added to each well. After 45 min of incubation at room temperature, absorbance was measured at $405 \mathrm{~nm}$. IFN- $\boldsymbol{\gamma}$ concentrations in the samples were determined against a standard curve of serially diluted recombinant mouse IFN- $\gamma$ and the measured protein concentration was used to express the values as $U$
IFN- $\gamma \mathrm{mg}^{-1}$ protein. The limit of detection was $0.5 \cup \mathrm{ml}^{-1}$. This value was the lowest standard with an absorbance greater than the blank $\pm 2 \mathrm{SD}$ and was significantly different from the blank wells $(P<0.05)$.

\section{NADPH diaphorase histochemistry}

Tissue was harvested from WT and NOS-2-/- mice at day 12 of gestation as described previously. The isolated implantation sites were fixed by immersion in $4 \%(\mathrm{w} / \mathrm{v})$ paraformaldehyde for $24 \mathrm{~h}$ at $4{ }^{\circ} \mathrm{C}$. The tissues were rinsed and treated with a $10 \%(\mathrm{w} / \mathrm{v})$ sucrose solution for $48 \mathrm{~h}$ and subsequently processed for cryosectioning. Sections of $10 \mu \mathrm{m}$ in thickness were cut from the centres of implantation sites and thaw-mounted on to positively charged glass slides. Sections were incubated with $1.0 \mathrm{mg} \mathrm{NADPH} \mathrm{ml}^{-1}$, $0.5 \%(\mathrm{v} / \mathrm{v})$ Triton-X100, $0.25 \mathrm{mg}$ nitro blue tetrazolium $\mathrm{ml}^{-1}$ in 0.1 mol Tris-buffer $\mathrm{I}^{-1}, \mathrm{pH} 8.0$, for $1 \mathrm{~h}$ at room temperature in a humidified chamber. After rinsing three times in $0.02 \mathrm{~mol} \mathrm{PBS} \mathrm{I}^{-1}$, $\mathrm{pH} 7.4$, the sections were counterstained with methyl green for $1 \mathrm{~min}$, placed in 95\% (v/v) ethanol and then dehydrated in $100 \%$ ethanol. The sections were cleared through three changes of Histoclear (National Diagnostics, Atlanta, GA) and a coverslip with Permount was added (Fisher Scientific, Fair Lawn, NJ).

\section{Immunoblot analysis}

Frozen tissues were homogenized in PBS containing a protease inhibitor cocktail (Complete; Roche, Nutley, NJ). The lysates were centrifuged at $8000 \mathrm{~g}$ and the supernatants were recovered for analysis. Protein concentrations were determined for each sample using the BioRad DC protein assay. Tissue supernatants and positive control supernatants were separated by SDS-PAGE under reducing conditions using a mini gel apparatus (BioRad). The separated proteins were then transferred on to nitrocellulose membranes (Schleister and Schuell, Keene, NH) in transfer buffer containing $25 \mathrm{mmol}$ Tris base (BioRad) $\mathrm{I}^{-1}, 192 \mathrm{mmol}$ glycine (BioRad) $\mathrm{I}^{-1}, 0.1 \%(\mathrm{w} / \mathrm{v})$ SDS and 20\% (v/v) methanol. The blots were blocked for $2 \mathrm{~h}$ in $3 \%(\mathrm{w} / \mathrm{v})$ nonfat dry milk (BioRad) in PBS and then incubated for $1 \mathrm{~h}$ at room temperature with one of the following antibodies: (i) mouse monoclonal anti-NOS-1 (BD Transduction Laboratories); (ii) mouse monoclonal anti-NOS-3 (BD Transduction Laboratories); (iii) rabbit polyclonal anti-NOS2 ; (iv) rabbit polyclonal anti- $\beta$-actin; (v) mouse normal IgG; or (vi) rabbit normal IgG. After washing the membranes in PBST, the blots were incubated with a 1:10 000 dilution of horseradish peroxidase-labelled secondary antibody of appropriate specificity for $1 \mathrm{~h}$ at room temperature. After washing five times with PBST, bound antibody was detected by chemiluminesence following the manufacturer's instructions (Pierce, Rockford, IL). The labelled membranes were then used to expose Hyperfilm ECL (Amersham Biosciences, Piscataway, NJ). Exposed film was scanned into an image analysis program (Gel-Pro; MediaCybernetics Silver Spring, MD) to measure the absorbance of the 
Table 1. Summary of reproductive efficiency in mice

\begin{tabular}{|c|c|c|c|c|c|c|}
\hline \multirow[b]{2}{*}{ Strain } & \multicolumn{3}{|c|}{ Number of viable embryos and pups } & \multirow{2}{*}{$\begin{array}{l}\text { Resorption } \\
\text { frequency }(\%) \\
\text { at days } 11-12 \\
\text { of gestation }\end{array}$} & \multirow{2}{*}{$\begin{array}{l}\text { Mass }(g) \text { of } \\
\text { newborn }\end{array}$} & \multirow{2}{*}{$\begin{array}{c}\text { Duration (days) } \\
\text { of gestation }\end{array}$} \\
\hline & Early gestation & Mid-gestation & Term & & & \\
\hline WT & $8.0 \pm 0.8(8)$ & $7.6 \pm 2.2(30)$ & $6.7 \pm 2.3(49)$ & $5.4(21)$ & $1.5 \pm 0.1(7)$ & $20.7 \pm 1.0(9)$ \\
\hline NOS-2-/- & $7.5 \pm 1.3(4)$ & $6.2 \pm 2.0(26)^{\mathrm{a}}$ & $6.1 \pm 1.6(59)^{\mathrm{a}}$ & $15.5(21)^{\mathrm{a}}$ & $1.4 \pm 0.1(7)$ & $20.4 \pm 0.5(7)$ \\
\hline
\end{tabular}

Values are mean $\pm \mathrm{SD}$. Values in parentheses represent the number of observations.

asignificantly different from WT $(P<0.05)$.

WT: wild-type mice; NOS-2--: mice deficient in the gene encoding nitric oxide synthase 2 (NOS-2).

specific bands. The absorbance of the NOS-3 specific band was normalized to the absorbance of $\beta$-actin and used to compare relative amounts of each NOS-3 enzyme in each sample.

\section{Results}

\section{Reproductive efficiency of NOS-2-/ mice}

Extensive data were collected from our breeding colonies to determine whether the lack of NOS-2 altered reproductive success. Several parameters were assessed, including duration of gestation, fecundity, birth weight and fetal resorption rates (Table 1 ). The average number of implantation sites early in gestation was similar for WT and NOS-2/- mice. However, by mid-gestation there were significantly fewer viable embryos in NOS-2/- mothers $(P<0.05)$. This finding continued throughout gestation as the NOS- $2^{--}$mice also had smaller litters than WT mice $(P<0.05)$. The frequency of fetal resorptions was also significantly higher in the NOS-2 deficient mice $(P<0.05)$. Lack of NOS-2 did not alter the birth weight of newborn mice or significantly affect the duration of gestation between WT and NOS-2-/- mice.

\section{Decidual abnormalities in NOS-2-- mice}

Histological assessment of haematoxylin- and eosinstained mid-gestation implantation sites under light microscopy indicated that lack of NOS-2 results in decidual phenotypic anomalies. The decidua of $\mathrm{NOS}_{-2}^{-/-}$mice showed a distinct lack of cellularity in comparison with decidua of WT mice (Fig. 1a,b). This apparent hypocellularity of the NOS-2-/- decidua was first identified on day 10 of gestation and was observed throughout the remainder of gestation. The degree of cellularity at midgestation was quantified by calculating the percentage of cellular material present in the decidua. There was a significant reduction in cellular area in NOS-2/- mice in relation to WT mice at days 10,12 and 14 of gestation (Fig. 2).

Although the decidual arteries of many species are modified during normal pregnancy (Pijenborg et al., 1981; Craven et al., 1998), distinct differences were observed between the decidual arteries of mid-gestation NOS- ${ }^{-/-}$and WT mice. Decidual vessels in NOS-2/- mice were charac- terized as having thickened arterial walls and smaller lumina than similar arteries in WT mice (Fig. 1c,d). Decidual arteries from two to five mothers at days 8, 10, 12 and 14 of gestation were quantified by image analysis in NOS- $2^{--}$and WT mice. The results showed that the vessel wall:lumen ratio was significantly increased in NOS- 2 mice (Fig. 3). Unusually thickened blood vessels in NOS-2 mice were restricted to the large arteries in the mesometrial aspect of the decidua subjacent to the circular muscle layer and were observed only on days 10,12 and 14 of gestation. Vessels in other anatomical compartments of the implantation site including the placenta and metrial gland appeared normal (data not shown).

\section{Immunohistochemical analysis}

A series of immunohistochemical experiments were undertaken to characterize the cells in the thickened vascular walls of the NOS- $2^{-/}$mice. In the first series of experiments, implantation sites of NOS-2/- and WT mice were stained for smooth muscle $\alpha$-actin. These experiments revealed that the perivascular cells of the decidual vessels had much lower $\alpha$-actin immunoreactivity compared with arteries elsewhere in the implantation site (Fig. 4a-f). This reduction in smooth muscle $\alpha$-actin occurred in decidual blood vessels of WT and NOS-2/- mice, as there was no observable difference in staining patterns between the two strains.

NO-cGMP signalling contributes to a secretory or synthetic phenotype in vascular smooth muscle cells (Boerth et al., 1997). As smooth muscle $\alpha$-actin, a marker of contractile smooth muscle, appeared low in decidual arteries, the expression of thrombospondin, a marker of the secretory smooth muscle phenotype, was also assessed. Positively stained cells were observed in the placentae of both NOS-2-/- and WT mice and in a mouse fibroblast cell line, L929, used as a positive control. However, no positive staining was observed in the decidual vasculature of NOS$2^{-/-}$or WT mice (data not shown).

The thickened decidual arteries of NOS-2-/- were also assessed for the expression of known markers for various types of cell. These experiments revealed that the thickened vessels were not composed of macrophages, trophoblasts or natural killer cells. As expected (Hunt et al., 2000), positive 

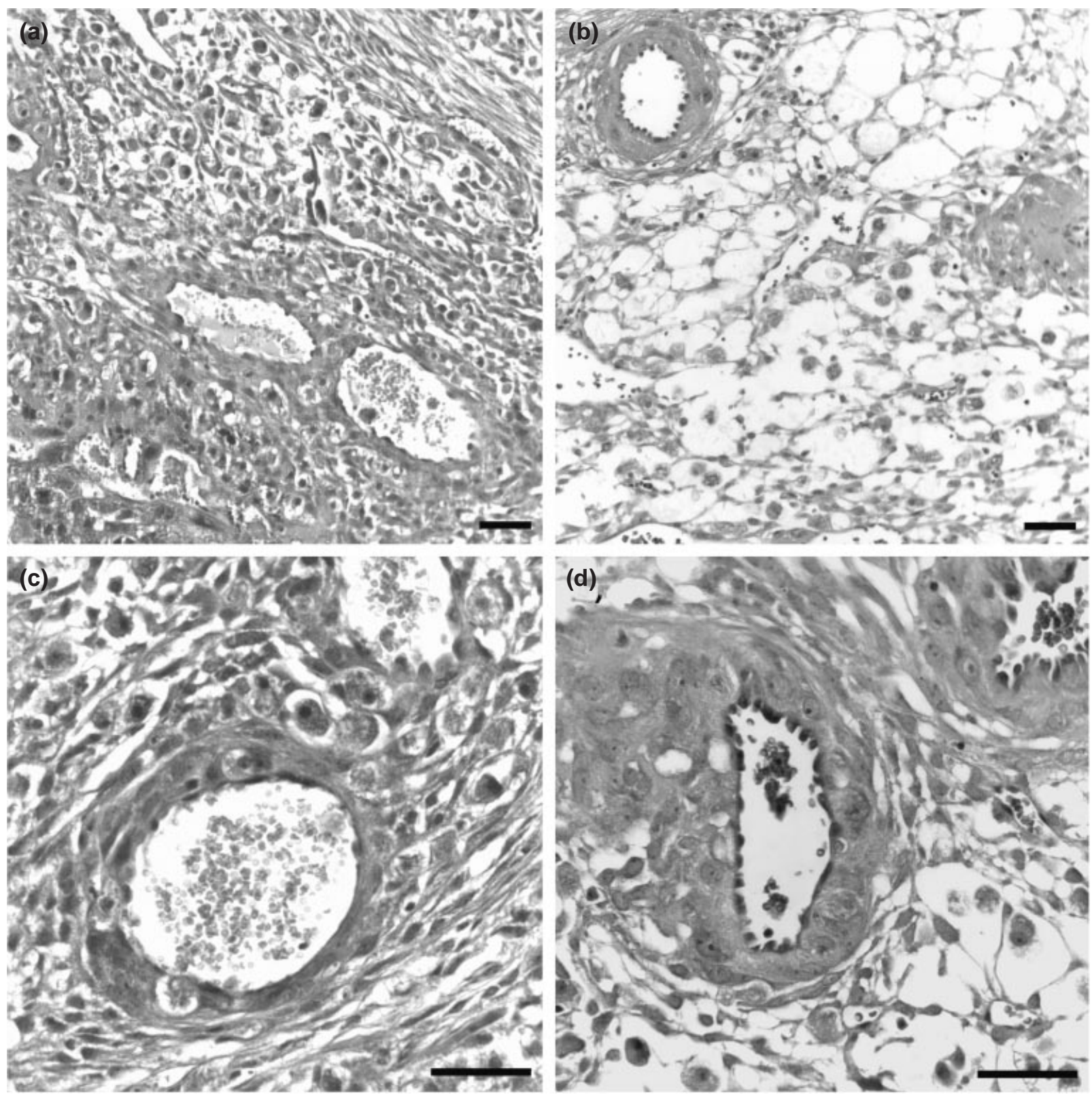

Fig. 1. Photomicrographs of decidua from $(a, c)$ wild-type mice and $(b, d)$ mice deficient in the gene encoding nitric oxide synthase $2\left(\mathrm{NOS}_{-} 2^{--}\right)$at day 12 of gestation. $(\mathrm{a}, \mathrm{b})$ Decidual cellularity and $(\mathrm{c}, \mathrm{d})$ typical decidual arteries. Scale bars represent $50 \mu \mathrm{m}$.

cells with the morphological features of tissue macrophages were observed within the longitudinal and circular smooth muscle layers of the pregnant uterus and in the connective tissue of the myometrium. In addition, implantation sites from NOS-2-/ mice had the expected localization of cytokeratin, which was restricted to trophoblasts in the placenta and uterine epithelial cells. The perivascular cells did not stain with PAS, indicating lack of glycoprotein content characteristic of uterine natural killer cells (data not shown).

\section{Quantification of IFN- $\gamma$}

IFN- $\gamma$ has been implicated as a key modulator of deci- dual cellularity and vascular structure (Ashkar et al., 2000). ELISA was performed to determine whether this cytokine was present in normal amounts at the implantation sites of NOS- $2^{--}$mice. The mean $U \mathrm{mg}^{-1}$ protein for WT mice was $0.19 \pm 0.03(n=4)$. IFN- $\gamma$ content was similar in NOS- $2^{-/}$ mice and on average was $0.16 \pm 0.03 \mathrm{U} \mathrm{mg}^{-1}(n=3)$ (data not shown).

\section{Assessment of compensatory NOS activity}

In many instances when a crucial gene is rendered null by genetic manipulations, other genes or redundant mecha- 


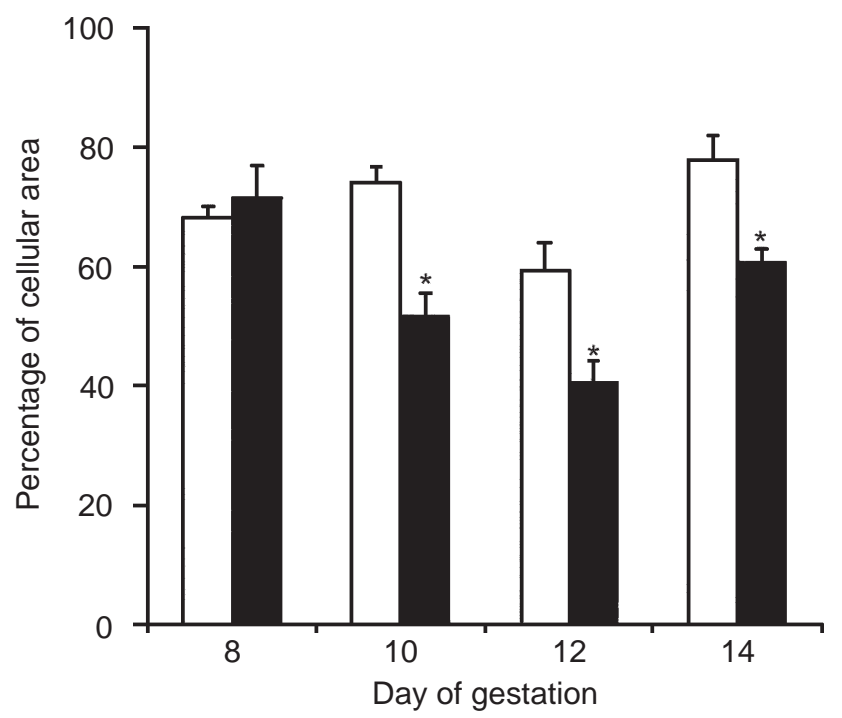

Fig. 2. Percentage ( \pm SEM) of decidua cellular area in wild-type (WT) mice ( $\square$ ) and mice deficient in the gene encoding nitric oxide synthase $2\left(\mathrm{NOS}_{\left.-2-{ }^{--}\right)}(\boldsymbol{\square})\right.$. Three implantation sites from three mothers were analysed for each day of gestation and each strain of mouse. ${ }^{*} P<0.05$ compared with WT mice.

nisms may functionally compensate for the lost gene. As NO can be generated by other NOS isoforms, NOS expression was assessed by histochemical techniques and immunoblot analysis. NADPH diaphorase histochemistry, which detects the activity of any NOS isoform, was performed on tissue sections collected from implantation sites at day 12 of gestation. This histochemical procedure revealed positive staining in the circular uterine smooth muscle, placenta, and most endothelial cells of the myometrium, metrial gland and decidual blood vessels (Fig. 4g-h). Qualitative analysis of 12 implantation sites from each mouse strain at day 12 of gestation revealed no apparent difference in the staining intensity or localization between WT and NOS-2 deficient mice (data not shown).

Immunoblot analysis was performed on mid-gestation placentae and uterine tissues (mesometrial decidua, circular smooth muscle and metrial gland) from WT and NOS-2- mice to assess any possible compensatory mechanisms in the NOS-2-- mice. It was not possible to detect NOS-1 in placenta or uterine tissue from three WT and three NOS-2\% mice, although a specific band of $155 \mathrm{kDa}$ was detected in a manufacturer-supplied positive control of rat pituitary gland (data not shown). As expected, a NOS-2specific band of $130 \mathrm{kDa}$ was detected in placentae and uterine tissues of WT, but not NOS-2-/ mice (data not shown). The antibody specific for NOS-3 detected a specific band of $140 \mathrm{kDa}$ in placentae and uterine tissues of both WT and NOS-2-- mice. This band correlated exactly with the band detected in a lysate of an endothelial cell line used as a positive control (Fig. 5a). Semi-quantitative analysis of the NOS-3 specific bands revealed that the expression was much higher in uterine tissues than in placenta and,

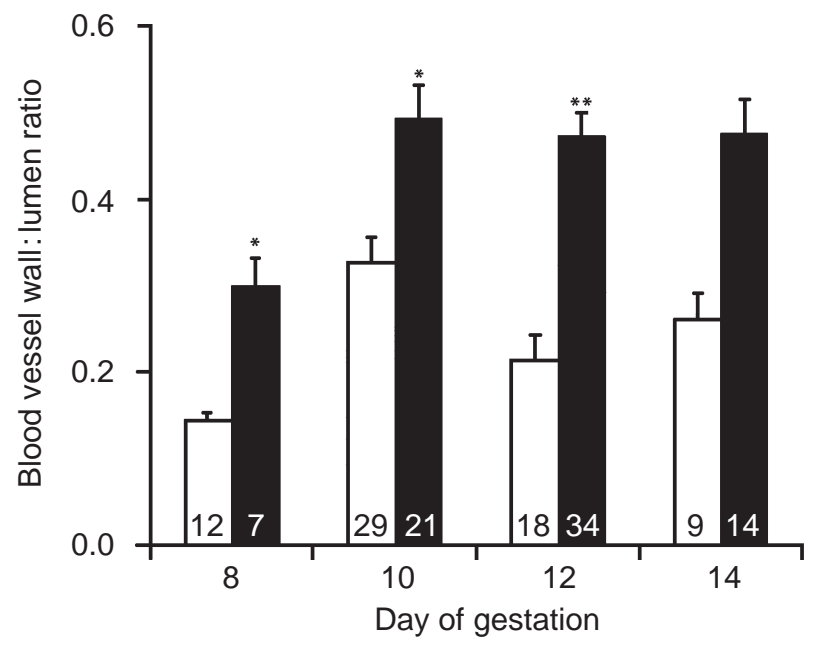

Fig. 3. The average ( \pm SEM) decidual blood vessel wall:lumen ratios in wild-type (WT) ( $\square$ ) mice and mice deficient in the gene encoding nitric oxide synthase 2 (NOS-2-/) $(\mathbf{\square})$. The numbers within the bars indicate the total number of vessels analysed from two to five mothers. ${ }^{*} P<0.05$ and ${ }^{* *} P<0.001$ compared with WT mice.

although slightly reduced in NOS- $2 \%$ mice, there was no significant difference in NOS-3 expression between WT and NOS-2- mice (Fig. 5b).

\section{Discussion}

NOS-2 is spatially and temporally in position to participate in processes important for normal gestation (Hunt et al., 1997). The present study describes some reproductive phenotypes of NOS-2-- mice that illustrate functional roles of NOS-2 in processes important for normal gestation.

The results of the present study evaluating the reproductive efficiency in NOS-2-- mice indicate that NOS-2 may have a limited role in the maintenance of post-implantation embryos throughout mid-gestation. There was not a significant decrease in litter size in early gestation, signifying that NOS-2 is not heavily involved in implantation or early developmental processes. This finding indicates that any role of NOS-2 in maintaining the litter throughout pregnancy is limited to mid-gestation. This finding correlates temporally with the expression of NOS-2, which reaches a peak at day 10 of gestation in normal pregnancies (Hunt et al., 1997). Although there is a subtle decrease in litter size, NOS-2-- mice were able to sustain the remaining pups to parturition, indicating that NOS-2 may have a supportive role in the maintenance of implanted embryos, but that it is clearly not required for the overall events of pregnancy. Moreover, the results of the present study that show normal gestation duration and birth weight in $\mathrm{NOS}-2^{-/-}$mice further limit conclusions regarding the role of NOS-2 in reproductive success to supporting embryo survival.

Histological assessment of implantation sites revealed substantial decidual anomalies in pregnant NOS-2-/- mice 
WT
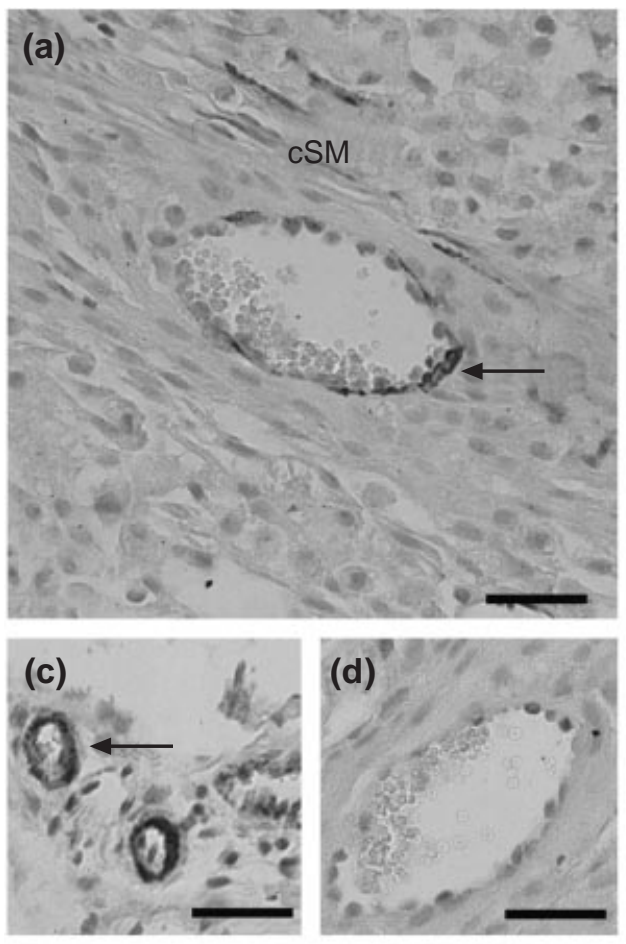

(g)

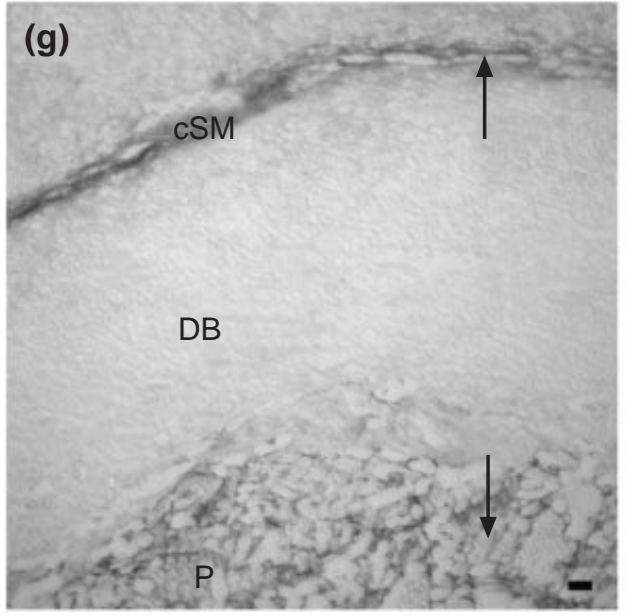

NOS-2 ${ }^{-1-}$
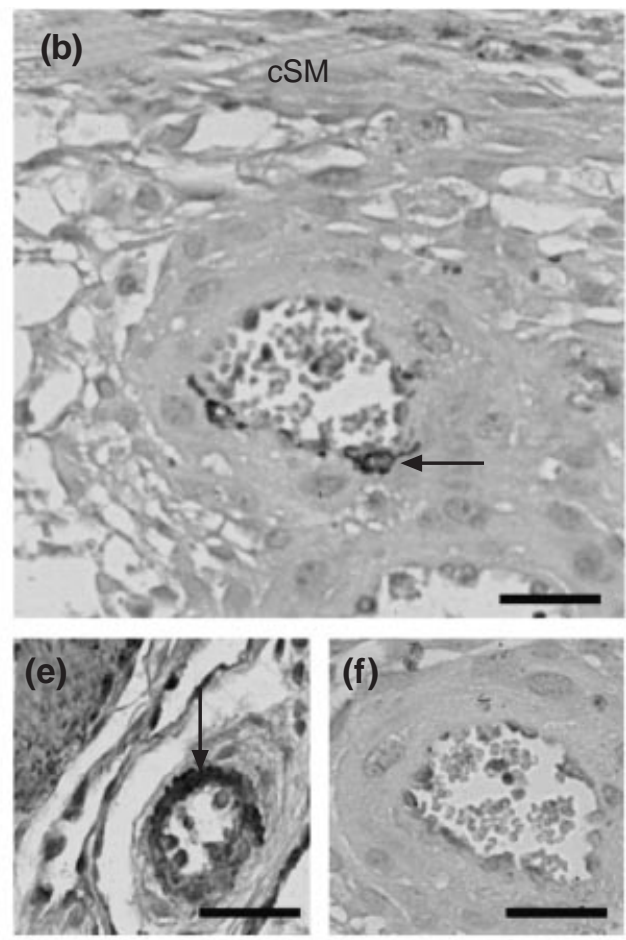

(h)

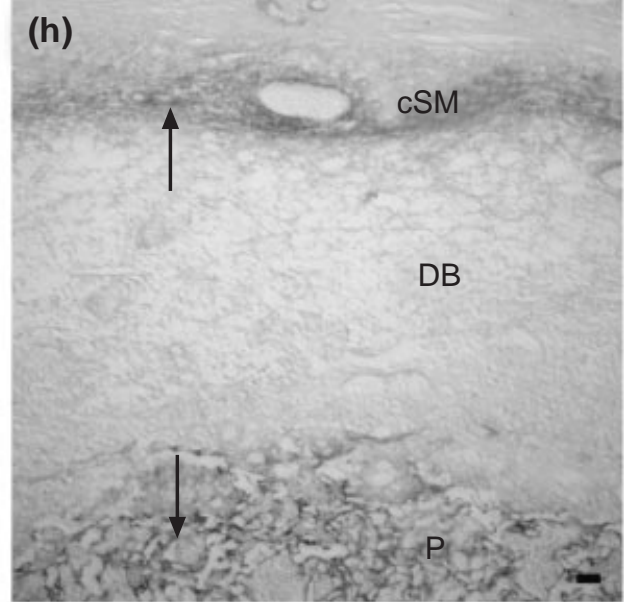

Fig. 4. (a-f) Photomicrographs of immunohistochemical staining for smooth muscle $\alpha$-actin in mice. Decidual arteries of (a) wild-type (WT) mice and (b) mice deficient in the gene encoding nitric oxide synthase 2 (NOS- $2^{-/-}$), and (c,e) arteries within the myometrial longitudinal smooth muscle in a section of mouse uterus embedded in paraffin wax at day 12 of gestation. (d,f) Adjacent sections are stained with mouse $\lg \mathrm{G}$ and serve as negative controls. (g,h) NADPH diaphorase staining of pregnant mouse uterus and placenta at day 12 of gestation. Low power photomicrographs of (g) WT and (h) NOS-2-- mouse implantation sites. Arrows indicate positively stained cells. cSM: circular smooth muscle; DB: decidua basalis; P: placenta. Scale bars represent $50 \mu \mathrm{m}$.

at mid-gestation. These results show a direct correlation between NOS-2 and processes required to establish or maintain proper decidual cellularity and decidual arteries. It has been established that uterine natural killer cells are directly involved in these processes (Guimond et al., 1997; Greenwood et al., 2000). Furthermore, the inhibition of
NOS while blocking progesterone during early pregnancy noticeably inhibits decidualization and reduces pregnancy outcome in rats (Chwalisz et al., 1999). Collectively, these results indicate that NOS-2 is a required component of the uterine natural killer cell-dependent vascular and decidual remodelling that occurs during pregnancy. 
(a)

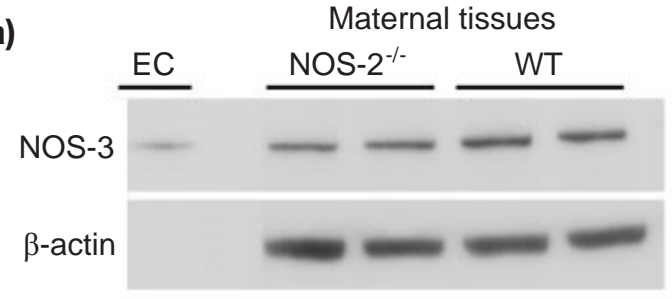

Placenta

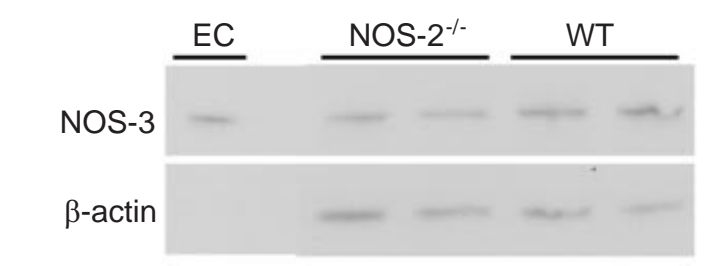

(b)

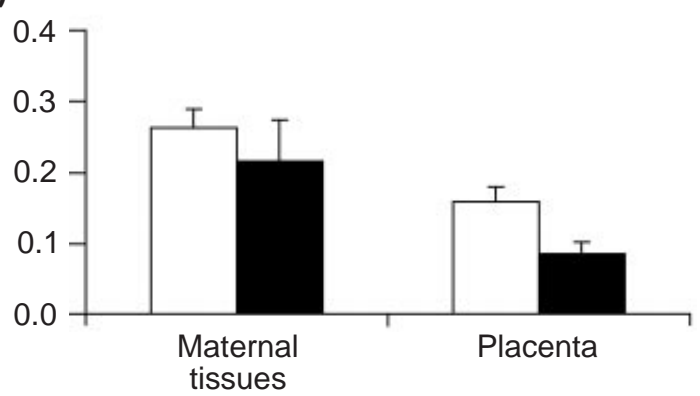

Fig. 5. Immunoblot analysis of uterine and placental lysates. (a) Uterine and placental lysates from wild-type (WT) mice and mice deficient in the gene encoding nitric oxide synthase 2 ( NOS-2--) probed with an antibody to nitric oxide synthase 3 (NOS-3) and $\beta$-actin at day 12 of gestation. (b) Comparison of the integrated absorbances of the NOS-3 bands relative to the $\beta$-actin bands of four NOS-2-- (ם) and three WT $(\square)$ mice. EC: endothelial cell lysate, positive control supplied with antibody.

The present study also attempted to characterize further the observed decidual vascular deformities in the NOS-2-mice by performing a series of immunohistochemical experiments. It was reasoned that if local concentrations of $\mathrm{NO}$ are reduced as a result of the absence of NOS-2, then this reduction might promote alterations in the expression of vascular smooth muscle phenotypic markers (Dey et al., 1998; Lincoln et al., 1998). It was concluded that there was no differential expression of the contractile protein $\alpha$ smooth muscle or thrombospondin, a marker of secretory smooth muscle. Additional experiments revealed that the thickened decidual vessels were not composed of macrophages, trophoblasts or natural killer cells.

Interestingly, the decidual arteries had an unusual pattern of $\alpha$-smooth muscle immunoreactivity. The decidual vascular smooth muscle cells showed weak, punctate staining, a profoundly different pattern from the complete ring of positive smooth muscle characteristic of arteries in other areas of the implantation site. This finding may indicate a reduction in the contractile properties and a de- differentiation of the vascular smooth muscle cells similar to that observed in other species (Nanaev et al., 1995).

It is possible that the altered decidual cellularity and thickened vasculature observed in the NOS-2 deficient mice cause the increased fetal loss during gestation. However, other mouse strains that share these decidual phenotypes show no evidence of reproductive compromise (Ashkar and Croy, 1999; Greenwood et al., 2000), indicating that other, undefined functions of NOS-2 are responsible for the increased frequency of fetal resorption observed in NOS-2-- mice. Perhaps the slightly reduced reproductive performance may reflect a lack of NOS-2 in the fetus or placenta. Indeed, NOS-2 has been detected in implanting mouse trophoblast cells and in rat placenta, and may participate in processes important for successful pregnancy (Purcell et al., 1997; Gagioti et al., 2000).

It has been shown that uterine natural killer cells of the pregnant uterus produce the pleiotropic cytokine IFN- $\gamma$ (Platt and Hunt, 1998), and recent studies indicate that decidual cellularity and vascularization are mediated by uterine natural killer cell-derived IFN- $\gamma$ (Ashkar et al., 2000). In the present study, quantification of IFN- $\gamma$ concentrations by ELISA revealed that NOS- $2^{-/}$mice express IFN- $\gamma$ at relatively normal concentrations in metrial gland and decidua at mid-gestation. Therefore, the decreased cellularity and altered decidual blood vessels observed in NOS-2-- mice cannot be explained by abrogation of the expression of IFN- $\gamma$. However, we cannot determine whether NOS-2 activity is dependent on IFN- $\gamma$ expression or whether these molecules regulate decidual cellularity and vasculature phenotype independently.

Finally, in the present study, NADPH diaphorase histochemical staining and immunoblot analysis for the various NOS isoforms indicate that the lack of NOS-2 is not functionally compensated for by altered localization or measurable increased expression of other NOS isoforms. However, the reproductive effects of NOS-2 deficiency may be masked by subtle increases in the activity of NOS-3. $\mathrm{NADPH}$ diaphorase staining shows that there is no difference in the localization of NOS activity between NOS-2 and WT mice. Given the fact that uterine natural killer cells are highly immunoreactive for NOS-2 (Hunt et al., 1997) and that immunoblot analysis of pregnant uterine tissue lysates detected a NOS-2 specific band, it was surprising that NOS activity was not detected in the uterine natural killer cells of WT mice by NADPH diaphorase staining. It may be that the NADPH diaphorase technique is not sufficiently sensitive to detect low amounts of NOS activity or alternatively the lack of positive staining may indicate that NOS-2 is not biologically active in the uterine natural killer cells.

Burnett and Hunt (2000) presented data showing that a uterine natural killer cell-specific cytotoxic molecule, perforin, is decreased in NOS-2 deficient mice. In this study it was reported that decidual anatomical aberrations and slightly reduced reproductive performance are also characteristics of NOS-2 deficient mice. The reproductive pheno- 
types described herein cannot be attributed to altered expression of IFN- $\gamma$ or the other NOS isoforms, as expression of IFN- $\gamma$ and NOS-3 was comparatively normal in the uteri of pregnant NOS-2- mice. Collectively, these observations support the main finding of the present study that NOS-2 has a critical role in controlling decidual and vascular differentiation at mid-gestation and may have a protective role against intrauterine fetal loss at mid-gestation.

The authors are grateful to C. Nathan (Weill Cornell Medical College, NY) for supplying breeding pairs of the NOS-2-- mice. This work is supported in part by grants from the National Institutes of Health to J. S. Hunt (HD24212, AI38502) and by the NIH P30 Kansas Center for Reproductive Sciences (HD33994).

\section{References}

Ali M, Buhimschi IA, Chwalisz K and Garfield RE (1997) Changes in expression of the nitric oxide synthase isoforms in rat uterus and cervix during pregnancy and parturition Molecular Human Reproduction 3 995-1003

Ashkar AA and Croy BA (1999) Interferon-gamma contributes to the normalcy of murine pregnancy Biology of Reproduction 61 493-502

Ashkar AA, Di Santo JP and Croy BA (2000) Interferon gamma contributes to initiation of uterine vascular modification, decidual integrity and uterine natural killer cell maturation during normal pregnancy Journal of Experimental Medicine 192 259-270

Austyn JM and Gordon S (1981) F4/80, a monoclonal antibody directed specifically against the mouse macrophage European Journal of Immunology 11 805-815

Boerth NJ, Dey NB, Cornwell TL and Lincoln TM (1997) Cyclic GMPdependent protein kinase regulates vascular smooth muscle cell phenotype Journal of Vascular Research 34 245-259

Burnett TG and Hunt JS (2000) Nitric oxide synthase-2 and expression of perforin in uterine natural killer cells Journal of Immunology 164 $5245-5250$

Chwalisz K, Winterhager E, Thienel T and Garfield RE (1999) Synergistic role of nitric oxide and progesterone during the establishment of pregnancy in the rat Human Reproduction 14 542-552

Craven CM, Morgan T and Ward K (1998) Decidual spiral artery remodeling begins before cellular interaction with cytotrophoblasts Placenta 19 241-252

Dey NP, Boerth NJ, Murphy-Ullrich JE, Chang PL, Prince CW and Lincoln TM (1998) Cyclic GMP dependent protein kinase inhibits osteopontin and thrombospondin production in rat aortic smooth muscle cells Circulation Research 82 139-146

Gagioti S, Scavone C and Bevilacqua E (2000) Participation of the mouse implanting trophoblast in nitric oxide production during pregnancy Biology of Reproduction 62 260-268

Greenwood JD, Minhas JP, Di Santo JP and Croy BA (2000) Ultrastructural studies of implantation sites from mice deficient in uterine natural killer cells Placenta 21 693-702

Guimond MJ, Luross JA, Wang B, Terhorst C, Danial S and Croy BA (1997) Absence of natural killer cells during murine pregnancy is associated with reproductive compromise in TgE26 mice Biology of Reproduction 56 169-179

Hunt JS, Miller L, Vassmer D and Croy BA (1997) Expression of the inducible nitric oxide synthase gene in mouse uterine leukocytes and potential relationships with uterine function during pregnancy Biology of Reproduction 57 827-836

Hunt JS, Petroff MP and Burnett TG (2000) Uterine leukocytes: key players in pregnancy Seminars in Cell and Developmental Biology 11 127-137

Lincoln TM, Dey NB, Boerth NJ, Cornwell TL and Soff GA (1998) Nitric oxide-cyclic GMP pathway regulates vascular smooth muscle cell phenotypic modulation: implications in vascular diseases Acta Physiologica Scandinavia 164 507-515

MacMicking J, Xie QW and Nathan C (1997) Nitric oxide and macrophage function Annual Review of Immunology 15 323-350

Molnar M, Suto T, Toth T and Hertelendy F (1994) Prolonged blockade of nitric oxide synthesis in gravid rats produces sustained hypertension, proteinuria, thrombocytopenia and intrauterine growth retardation American Journal of Obstetrics and Gynecology 170 1458-1466

Moncada S, Palmer RM and Higgs EA (1991) Nitric oxide: physiology, pathophysiology and pharmacology Pharmacological Reviews 43 109-142

Nanaev AK, Chwalisz K, Frank HG, Kohnen G, Hegele-Hartung C and Kaufmann P (1995) Physiological dilation of uteroplacental arteries in the guinea-pig depends on nitric oxide synthase activity of extravillous trophoblasts Cell and Tissue Research 282 407-421

Nathan C and Xie QW (1994) Nitric oxide synthases: roles, tolls and controls Cell 78 915-918

Norman JE, Thompson AJ, Telfer JF, Young A, Greer IA and Cameron IT (1999) Myometrial constitutive nitric oxide synthase expression is increased during human pregnancy Molecular Human Reproduction $\mathbf{5}$ 175-181

Peel S (1989) Granulated metrial gland cells Advances in Anatomy, Embryology and Cell Biology 115 1-11

Pijnenborg R, Robertson WB, Brosens I and Dixon G (1981) Review article: trophoblast invasion and the establishment of haemorchorial placentation in man and laboratory animals Placenta 2 71-92

Platt JS and Hunt JS (1998) Interferon-gamma gene expression in cycling and pregnant mouse uterus: temporal aspects and cellular localization Journal of Leukocyte Biology 64 393-400

Purcell TL, Buhimschi IA, Chwalisz K and Garfield RE (1997) Inducible nitric oxide synthase is present in the rat placenta at the fetal-maternal interface and decreases prior to labor Molecular Human Reproduction 3 485-491

Radomski MW (1995) Nitric oxide: biological mediator, modulator and effector Annals of Medicine 27 321-329

Sladek SM, Kanbour-Shakir A, Watkins S, Berghorn KA, Hoffman GE and Roberts JM (1998) Granulated metrial gland cells contain nitric oxide synthases during pregnancy in the rat Placenta 19 55-65

Yallampalli C and Garfield RE (1993) Inhibition of nitric oxide synthesis in rats during pregnancy produces signs similar to those of pre-eclampsia American Journal of Obstetrics and Gynecology 169 1316-1320

Received 30 November 2001.

First decision 19 February 2002.

Accepted 8 March 2002. 